\title{
A LANDMARK IN THE FIELD OF GENOME SIZE EVOLUTION: MARIA GABRIELLA MANFREDI ROMANINI'S CONTRIBUTIONS
}

\author{
CARLOALBERTO REDI (*), SILVIA GARAGNA (**), \\ ERNESTO CAPANNA (***)
}

SunTO. - L'interesse di Maria Gabriella Manfredi Romani (MGMR, come affettuosamente tutti gli allievi chiamavano la professoressa) per le dimensioni del genoma risale agli inizi della sua carriera accademica. Dalla Antropologia fisica che tanto la affascinava fu presto capace di cogliere le innovazioni che la rivoluzione molecolare stava portando nei paradigmi concettuali delle discipline classiche. Seguendo gli insegnamenti del Suo maestro Maffo Vialli divenne in breve tempo un punto di riferimento a livello internazionale per le ricerche di citochimica del DNA. Grazie alla applicazione delle più recenti tecniche citofotometriche (alle quali in parte dedicò tante energie per svilupparne di nuove) fu in grado di stabilire un centro internazionale al quale studiosi di ogni parte del pianeta si rivolsero. Certamente il sodalizio, non solo scientifico, con Ernesto Capanna segnò buona parte degli avanzamenti concettuali ai quali giunse.

Riconoscimento più esplicito di quanto prodotto ed insegnato: il grande affetto che allievi e colleghi hanno sempre dimostrato ed ancora oggi manifestano.

$* * *$

ABSTRACT. - The interest for genome evolution started quite early during the academic career of prof. Maria Gabriella Manfredi Romanini (MGMR, as all her pupils were used to call her; she knew that, and she was pleased we were confidentially nicknaming her!).

(*) Dipartimento di Biologia e Biotecnologie "Lazzaro Spallanzani"; Università degli Studi di Pavia, Via A. Ferrata 9, 27100 Pavia, Italy.

E-mail: carloalberto.redi@unipv.it

${ }^{(* *)}$ Dipartimento di Biologia e Biotecnologie "Lazzaro Spallanzani”; Università degli Studi di Pavia, Via A. Ferrata 9, 27100 Pavia, Italy.

${ }^{(* * *)}$ Dipartimento di Biologia e Biotecnologie "Charles Darwin"; Università di Roma "La Sapienza", Via Alfonso Borelli 50, 00161 Roma, Italy. 
She taught Anthropology since 1964 while holding the course of Histology and Embryology for the degree in biology. She was immediately attracted by the new coming vision that shifted from the physical anthropology to the molecular level at which the human evolution could be followed. Strong believer, she never put her beliefs before the scientific data: she invited us (her pupils and students) to read carefully Pierre Teilhard de Chardin, a great palaeontologist who took part in the discovery of the Peking man but, at that time, also an heterodox Jesuit philosopher whose writing were censored by the Catholic Church because of his view of the original sin and the evolutionary theories. At the same time, MGMR was often stressing that we had to learn all of the new coming techniques to get a deep vision of the evolutionary story of the Mammals. Just to remember one of her teachings of the ' 60 , she convinced all of us to carry on the new techniques of DNA denaturation and hybridization by simply using hot water solutions and cold ice! (a technique that stimulated inspiration to an entire generation of biologists). She was continuously teaching, even during the summer holidays when she was asking all of us to come to her lake's villa (discomforting her husband, that rightly was recalling MGMR that was already dinner time!) and inspiring curiosity, fascination for the livings and wishes to fully participate to the international academic community. Over time, she inspired even the F2 of her pupils thanks to her enthusiastic and positive view for our exceptionally lucky chance to carry on the "most marvellous work", as she defined our job. Having much younger pupils she was always able to learn even the most advanced molecular techniques that she always tried to apply even in very difficult environmental situations (while the Italian Universities only encountered a drastic shortage of human capitals and economic resources): she prompted us to go abroad to collaborate with the best institutions worldwide (Germany, Holland, France, England, Japan, Brazil, to mention a few). While teaching and doing research she took the very hard gamble to launch at an international level the European Journal of histochemistry (born as "Rivista di Istochimica normale ed applicata", the first journal on Histochemistry worldwide, founded on 1954 by her tutor and master, Maffo Vialli).

Here we will briefly present one of the many interest and activities carried on by Maria Gabriella Manfredi Romanini; the one on Mammalian genome size, especially looking at the deep human and scientific relationships she had (apart with the coauthors who were her pupils) with Ernesto Capanna.

Maria Gabriella Manfredi Romanini indeed worked out standardsetting papers in the field of genome size (GS) and evolution with the great capacity to highlight future investigations and to provide room for other studies. To support this sharply cut sentence the readers are invited to scan GS databases so that quite clearly the fundamental contributions of MGMR will clearly appear. Just consider the followings websites, each housing tens and tens of MGMR originally measured GSs:

DOGS (Database of Genome Sizes). This covers 301 organisms and is directed by Søren Brunak, Center for Biological Sequence Analysis, Technical University of Denmark, Lyngby: www.cbs.dtu.dk/ databases/DOGS/index.php. 
Genome (Animal) Size Database. This offers C-values from about 1300 invertebrates and 2500 vertebrates and is maintained by Ryan Gregory, University of Guelph, Canada: www.genomesize.com.

GOLD (Genomes Online Database). This represents a Web resource for genome projects worldwide, referring to 463 eukaryotic genomes, and it is maintained by Nikos C. Kyrpides, Lawrence Berkeley National Laboratory, Berkeley, California: www.genomesonline.org.

KEGG (Kyoto Encyclopedia of Genes and Genomes). This provides (among other things) a database of genome projects with 243 entries, and it was set up by Minoru Kanehisa at Bioinformatics Center, Institute for Chemical Research, Kyoto University, Tokyo: www.genome.ad.jp/kegg.

In addition the "DBA, Mammalian Genome Size Database," hosted by the Dipartimento di Biologia Animale, Pavia University, Italy, which has 237 data sets and it is managed by one of the MGMR pupil, Daniele Formenti: http://www-3.unipv.it/webbio/dbagsh.htm.

To stress the relevance of the MGMR's contributions to the GS and genome studies one can simply recall that just two papers worked out by Italians (in Italy!) are quoted in the draft of the human genome (Venter et al., 2001); that by Giorgio Bernardi on the isochores and that entitled: "Nuclear DNA Content and Morphology of the Karyotype in Certain Palearctic Microchiroptera" by MGMR and one of us (Capanna and Manfredi Romanini, 1971). This fact alone speaks out, no further words needed, the right metric to tell the readers how much the works carried out by MGMR are relevant to understand genome evolution (size, structure and composition). But the story starts quite a long time before the publication of that paper: the story starts with the meeting between MGMR and Ernesto Capanna. It was the end of the '60, at around the mythical '68, a period that was so interesting for MGMR: during her classes, she was always urging her young students to participate to the extramural life in order to renew the instruction system and to pretend, with a serious and dedicated behaviour, a new University, dreaming for a more free and right society; in those years, Capanna had the opportunity to meet MGMR, and they immediately realized to have a common interest in vertebrate evolution; MGMR was already interested in GS variation in Primates while Capanna was interested in the structural karyotype variations that quite often accompany vertebrate evolution. So it was quite natural that both started a collaboration that lasted an entire academic life. They started to measure the 
GS of some representatives of Chiroptera. With great surprise, they found out that the Chiroptera GS was among the smallest for Eutheria; they cleverly correlated this with the metabolic needs for flying. In other words, they anticipated a concept that would have become a landmark for the genetic epistemological meaning of the GS in the years to come: an adaptive Mammals strategy to fly. A direct proof supporting their new concept, so that it was possible to put under verification such anticipatory idea, was easy to design: if they were correct, one could anticipate that flying birds should have a smaller average GS than runner birds. And they proved this hypothesis by measuring the GS of 48 bird species! It was thus possible to confirm that Chiroptera and flying birds got a minimal genome size which is adaptive for the metabolic requirements of those groups (anyway, one of the multifaceted meanings of GS). Later we will come back to this concept, but let us recall the whole story since today we are celebrating MGMR's memory.

Already the great Susumo Ohno (1928-2000), in another landmark contribution to the field of genome evolution (Evolution by gene duplication), highlighted that big genomes should be prospectively relevant for those evolutionary ancestral lines spreading out later on several different clades, which will become basal for the extant terrestrial vertebrates groups. His famous aphorism "Majus redundantiae, majus evolutionis" is perfectly tailored to those big genomes of the Dipnoans and Amphibians, witness of those hypothetical big genomes that we attribute to the Paleozoic Rhipidistia and Labyrinthodonts. The idea of MGMR and Capanna was slightly different from that of Susumo Ohno, since the earlier was applied just to macroevolutionary processes and not to the megaevolutionary aspects considered by Susumo (we all remember him to play DNA sequence strings at the piano for our pleasure in Uppsala, during the tenth International Chromosome Conference, 1989). The hypothesis by MGMR and coworkers was that the GS differences inside a class is due to quantitative variations of the non-coding DNA, in other words in quantitative variations of heterochromatin. Thus, Ohno's aphorism should be read (while correcting his latin!): "Tam maior heterochromatina, quam maior evolutio".

Therefore, it was quite natural that MGMR and Capanna tried to look at an ideal model to test such idea, since the GS variation observed into the model considered till then (Chiroptera) could be attributed to the different tested families of bats. To hold true the aphorism it should be necessary to prove it at a much small systematic scale, to a much lim- 
ited systematic group variation, ideally at the level of species or subspecies. The ideal structural rearrangement was easily chosen: obviously, it was the Robertsonian (Rb) fusion of two acrocentrics chromosomes. The existing models to explain the $\mathrm{Rb}$ fusion entailed (minimal) DNA losses at the telomeric or sub-telomeric level. Thus, the possible GS variation due to structural chromosomal rearrangements should be tested in an animal model where massive Rb fusions occur; in this way, the sensitivity of the method used to quantify the GS variation could match the quantity of DNA losses, at least theoretically. We were still in the era of the quantitative cytophotometric methods, not yet in the nonradioactive molecular probe hybridization era! The ideal animal model was "served on a silver dish" by Alfred Gropp (1924-1983), who in those years was describing several $\mathrm{Rb}$ mouse populations across the Alps system. Alfred was a romantic lover of the Italian lakes and mountains (he was such a deep lover of life in any of its expressions: nature first, science, history, people, arts, culture, travels and so fond of his knowledge of the Italian culture!) and while moving around in that area he got the idea to check for the karyotype of the Val Poschiavo mice (Swiss canton Grigioni). Astonishingly enough, he was able to show that those mice, already described by the Swiss zoologist Fatio (Victor Fatio de Beaumont, 1838-1906) as Mus poschiavinus, were carriers of seven couples of big metacentrics reducing the standard mouse karyotype of $2 n=40$ to a $2 n=26$ karyotype (thus justifying the attribution of the species rank to those mice, otherwise totally similar, anatomically speaking, to the wild mice of the West European countries). The Poschiavo mice were known as "la souris du tabac" (worldwide known, after the yankee translation, as tobacco mouse). Heinz Winking (a pupil of Alfred Gropp) was presenting this datum as a work "in progress" at a meeting in Brno in 1971. Since then, we have been doing cytophotometric evaluations of GS for all of the new mouse populations that some of us were trapping all around Europe. We all deeply contributed to show that a great mosaic of $\mathrm{Rb}$ populations, scattered throughout all West Europe, was the characteristic feature of the $\mathrm{Rb}$ rearrangements occurring in a standard 40 acrocentrics chromosomes karyotype. Clearly, the understanding of the evolutionary phenomenon of different $\mathrm{Rb}$ karyotypes fixation at the level of each single population was calling for a molecular explanation (at least for the high rate of $\mathrm{Rb}$ rearrangements occurrence) helping to understand the Darwinian level of the $\mathrm{Rb}$ karyotype diversification phenomenon: thanks to the chromosomally 
derived subfertility or sterility of the hybrids (which occur when and where two different $\mathrm{Rb}$ populations meet) the two populations may remain separated. But one has to devise a model were in spite of that subfertility the new $\mathrm{Rb}$ rearrangements can fix themselves in the new arising karyotype! We called the "thanks to, in spite of" paradox the way the new $\mathrm{Rb}$ populations arise and stabilize. We were able to suggest a molecular model for the $\mathrm{Rb}$ rearrangements quite different from the simple prevailing idea of simultaneously occurring breaks at the subtelomeric level of two acrocentrics that rejoin in a metacentric later on. A model that, proudly enough for ourselves, was approved by Francis Crick who told us by phone "yes, it works and it makes sense!". We were able to talk to Francis Crick after several letters dispatched to him while he was visiting Kurt Benirscke in San Diego: first he received by priority mail our manuscript (those were days of pen-writing, no internet!) and than he was kind enough to answer (and thus in the published paper, Redi et al., 1990, we acknowledged the time spent for us). MGMR was very happy for our self-esteem when we reported her the Crick's words, and this aspect of great generosity was indeed a particular trait of her sensitivity. At the end we were able to show how the Rb fusion occurs, and publishing several papers explaining its molecular bases (and getting the front page of the prestigious Chromosoma); hence, we could suggest the way the non-Darwinian forces act in a selfassembling manner and how the $\mathrm{Rb}$ fusion later on becomes exposed to the Darwinian forces. During 1998, the two mammalogists' societies, the European (Societas Europaea Mammologica) and the American (American Society of Mammalogists), jointly carried on their annual meeting in Santiago de Compostela (12-14 July, 1998) were we presented a plenary lecture "Selfish or not selfish?" explaining the Hamlet's dilemma with the sub-title "The role of Heterochromatin in Mammal Evolution". We then wrote a long review on this topic, nonetheless we have to admit that this was done thanks to the day-by-day discussions we had with MGMR ! In those years she was reaching the same idea we were developing (so we all were literally "at school"!) studying several animal models: the Amphybians for which she had privileged discussions with Ettore Olmo and Alessandro Morescalchi, but certainly her loved monkeys and pro-monkeys she studied with so many scientists worldwide first of all, with her pupil Daniele Formenti but certainly with many other, younger and older, colleagues among whom Brunetto Chiarelli, Roscoe Stanyon, Yves Rumpler and Bernard Dutrillaux). The 
long review we wrote came out even thanks to the help of another great friends of us, Helmuth Zacharias, who is an expert of heterochromatin biology as well as a great historian of the heterochromatin concept, starting from the idea proposed in 1928 by the father of the heterochromatin, Emil Heitz (1892-1965). Basically, the idea was that the quantitative variation in heterochromatin (coming from the non-Darwinian world by self properties or just by chance) enters the Darwinian world. Accumulation of heterochromatin inducing large GS assigns (grants) slower cell cycle and metabolic features, whereas, in case of heterochromatin loss reducing the GS, faster features occur.

Thanks to the collaboration with the great Osvaldo Reig (19301998) and his school (Marisol Aguilera and her beloved pupil Antonio Perez-Zapata, 1954-1998) we were encouraged by MGMR to measure South American and Australian Marsupials and the Xenarthra GS; the simple idea was that the sluggish sloth (Bradypus tridactylus) should have a large GS. This was the case, but life is always so creative that for our displeasure all the other Xenarthra GS (both Pilosa and Cingulata) we measured showed large GS. So, during one of the many discussions we had it comes out that probably Susumo Ohno was right (at least inside the Mammalia class!), in the sense that the oldest phyletic lines should have larger GS that the new arisen ones. The story entails many other memorable moments we had the privilege to spend with MGMR; however, we would like to conclude this tribute to her human and scientific life, so generously able to inspire our activities, remembering the probably last (never say never!) contribution that the MGMR's school of the GS gave to the scientific community. We dedicated to MGMR's memory the front page and the entire paper that Journal Molecular Evolution published (Redi et al., 2007) after we measured the GS of six selected representatives across the Afrotheria supraordinal group, using static microphotometry on Feulgen stained nuclei of cultured fibroblasts: we compared, by datamining GS databases, the average GS found for this group with those we got for 373 placental mammals (less than $10 \%$ of the $4000-4500$ extant mammalian species): just one afrotherian GS (still that of the pioneering 1950's work on the aardvark Orycteropus afer GS, 5.86 pg of DNA), 15 Xenarthra, 112 Laurasiatheria and 245 Euarchontoglires. Thus, we demonstrated that the GS values of the Afrotheria are among the highest so far recorded for placental mammals, and that the mean GS value of Afrotheria $(5.3 \pm 0.7 \mathrm{pg})$ is the highest reported for the extant Placentalia. In addi- 
tion, we were able to show that the mean GS values of the Southern Hemisphere clades, Afrotheria and Xenarthra, are larger than those of the Northern Hemisphere clades, Laurasiatheria and Euarchontoglires: that is, each of the four supraordinal clades appears to be characterized by genomes that differ in size. Our data provided a novel genomic signature for the enigmatic Afrotheria group and proved to be of relevance for comparative genomics and molecular phylogenies, providing additional support for a basal position for Afrotheria. In fact, anatomical data (e.g., cranial, postcranial, and dental characteristics of extant and fossil species) provide evidence for the traditional systematic classification of mammals. In sharp contrast, nucleotide sequences suggest a southern (Gondwana) ancestry for mammals and an evolutionary scheme that partitions the extant placental (Eutherian) mammals into four major supraordinal clades: Afrotheria, Xenarthra, Laurasiatheria, and Euarchontoglires. These groupings result in an odd collection of animals if viewed in the light of traditional schemes. Afrotheria is one of the most remarkable hypotheses in mammal evolution: it suggests that nearly one-third of the orders of placental mammals form an endemic African clade that includes elephant shrews (Macroscelidea), golden moles (Chrysochloridae), tenrecs (Tenrecidae), aardvarks (Tubulidentata), hyraxes (Hyracoidea), elephants (Proboscidea), and the dugongs and manatees (Sirenia). Our data on the GS variation clearly provide novel genomic signatures in favour of the molecular phylogenetic analyses, supporting the emerging phylogeny for the extant Placentalia that radically departs from the morphologically based constructions of the past. Obviously enough, it calls for a functional explanation for what we observed.

Thus, coming back to MGMR's and Capanna's idea about the small GS of Chiroptera, we recalled the suggestions of MGMR about a possible functional interpretation of the GS meaning, so that it was obvious for us to suggest that the larger genomes in the Southern Hemisphere clades, especially Afrotheria, can be explained on that basis.

More recently, we have been invited to write a review on these ideas for Cytogenetics and Genome Research (Redi and Capanna, 2012): so, we took advantage of this possibility to stress that there are numerous data (both on small taxonomic groups and across a whole class) showing that the body mass-corrected metabolic rate of homeotherms decreases with latitude (i.e., there is a positive association). The general reason is straightforward: there is no need for additional body warming, 
which is necessary at the higher latitudes (but there are also other causes in separate cases: e.g., the shortage of water). At the same time, there is a negative correlation between body mass-corrected metabolic rate and GS. Taken together, these two phenomena could provide a functional explanation for the GS variation: thanks MGMR for your premonitory idea!

\section{REFERENCES}

Capanna E, Manfredi Romanini MG, 1971. Nuclear DNA Content and Morphology of the Karyotype in Certain Palearctic Microchiroptera. Caryologia 24:471-82.

Redi CA, Garagna S, Capanna E, 1990. Nature's experiments with in situ bybridation? A bypothesis for the mechanism of Rb fusion. J Evol Biol 3:133-7.

Redi CA, Garagna S, Zuccotti M, Capanna E, 2007. Genome size: a novel genome signature in support of Afroteria. J Mol Evol 64:484-6.

Redi CA, Capanna E, 2012. Genome Size Evolution: Sizing Mammalian Genome. Cytogenetics Genome Res 137:97-112.

Venter JC, et al., 2001. The sequence of the buman genome. Science 291:1304-51. Erratum in: Science 2001;292:1838. 